\title{
Enzymatic Determination of Unbound $D$-Mannose in Serum
}

\author{
Elja Pitkänen ${ }^{1}$, Olli Pitkänen $^{2}$ and Lasse Uotila ${ }^{1}$ \\ ${ }^{1}$ Kliinisen kemian laitos, Helsingin yliopistollinen keskussairaala, Helsinki, Finland \\ ${ }^{2}$ Lasten ja Nuorten sairaala, Helsingin yliopistollinen keskussairaala, Helsinki, Finland
}

Summary: Mannose is an aldohexose component of a number of glycoproteins in cellular membranes and blood plasma. Free (unbound) mannose is a normal blood plasma constituent and its concentration is elevated in diabetes mellitus and chronic glomerulonephritis. We devised an enzymatic method for the determination of free mannose in which mannose is converted to glucose-6-phosphate and measured spectrophotometrically using glucose-6-phosphate dehydrogenase and nicotinamide adenine dinucleotide phosphate (NADP). Accumulation of reduced NADP in the assay was verified by spectral analysis and by finding rapid disappearance of absorbance at $340 \mathrm{~nm}$ on addition of glutathione reductase and oxidized glutathione into the reaction mixture.

The method necessitates prior removal of glucose from the samples. This we accomplished using glucose-6-phosphate dehydrogenase and a surplus amount of NADP, followed by elimination of reduced NADP by acidification of the reaction mixture. The assays may be run in parallel for expediency.

Concentration of free mannose in serum was $18.5 \pm 5.5 \mu \mathrm{mol} / 1$ in healthy fasting female adults. The analytical recovery was $90.2 \pm 10.2 \%$ and the between-run imprecision was $13.5 \%(18.5 \pm 5.5 \mu \mathrm{mol} / \mathrm{l}$, mean $\pm \mathrm{SD})$ and $10.4 \%(75.3 \pm 10.3 \mu \mathrm{mol} / \mathrm{l})$. The assay showed rectilinearity up to $220 \mu \mathrm{mol} / 1$, which covers the measuring range to which the mannose concentrations in normal and clinical samples may be expected to fall.

\section{Introduction}

Mannose is an important carbohydrate component of glycoproteins that are attached to the cellular membranes. Furthermore, mannose is an oligosaccharide constituent of fibrinogen, apolipoproteins, immunoglobulins and numerous other glycoproteins that circulate in blood plasma. Changes in the content of protein-bound hexoses in diseases have been reported (1-4).

Mannose is incorporated in endoplasmic reticulum into the oligosaccharide assembly of glycoproteins using a pathway with phosphorylated dolichol as the sugar acceptor and transfer vehicle. Mannose is synthesized from glucose via a cellular enzymatic pathway through phosphorylated hexose intermediates. It is possible that the trimming of oligosaccharides of newly synthesized glycoproteins in the Golgi apparatus and the lysosomal breakdown of glycoproteins form other sources of intracellular mannose.

The concentration of free (unbound) mannose in human plasma has been measured with enzymatic methods $(5$, $6)$ and by means of gas-liquid chromatography (3, $7-10$ ) or gas-liquid chromatography/mass spectrometry (11). The enzymatic methods build on the use of a chain of enzyme reactions to convert mannose to glucose phosphate and the subsequent measurement of the glucose-6-phosphate formed. The technique necessitates prior elimination of glucose from the samples of serum, as glucose concentration greatly overruns the concentration of mannose. Elimination of glucose has been accomplished using glucose oxidase and catalase. However, the use of glucose oxidase is charged with the provision that the enzyme has slight oxidizing activity on mannose (12) and during removal of glucose some loss of mannose may occur.

In the present study the content of glucose and fructose in the samples was reduced using hexokinase ${ }^{1}$ ), glucose6-phosphate dehydrogenase ${ }^{1}$ ), and glucose-6-phosphate isomerase $^{1}$ ) in the presence of adenosine triphosphate (ATP) and nicotinamide adenine dinucleotide phosphate (NADP). Glucose and fructose were converted to glucose-6-phosphate in the reaction and then oxidized to 6phosphogluconate. Reduced NADP that accumulated in the reaction was destroyed by acidification of the reaction mixture (13). Mannose was then converted to glucose-6-phosphate by mannose-6-phosphate isomerase and glucose-6-phosphate isomerase, and the amount of glucose-6-phosphate formed was estimated by spectrophotometric measurement of the increase in absorbance at $340 \mathrm{~nm}$ in the presence of glucose-6-phosphate dehy-

\footnotetext{
1) Enzymes:

Hexokinase (EC 2.7.1.1)

Glucose-6-phosphate dehydrogenase (EC 1.1.1.49)

Glucose-6-phosphate isomerase (EC 5.3.1.9)

Glutathione reductase (EC 1.6.4.2)

Mannose-6-phosphate isomerase (EC 5.3.1.8)
} 
drogenase and NADP $(5,6,14)$. The sequence of reactions is outlined in figure 1 .

\section{Methods}

\section{Reagents}

$D$-glucose/ $D$-fructose UV-test kit and mannose-6-phosphate isomerase enzyme suspension were purchased from Boehringer (Mannheim, Germany). D-mannose, oxidized glutathione, yeast glutathione reductase (Grade III, 2500 units $/ 0.7 \mathrm{ml}$ ) and NADP were purchased from Sigma Chemical (St. Louis, MO, USA). ATP was obtained from Merck (Darmstadt, Germany). Sephadex G-25 PD-10 columns were purchased from Pharmacia, Uppsala, Sweden.

\section{Procedure}

The solutions of $D$-glucose/ $D$-fructose UV-test kit were modified for the determination of mannose.

\section{Preparation of working solutions}

The buffer solution (designated solution 1 in the test kit): To $6 \mathrm{ml}$ of the buffer solution $10 \mathrm{ml}$ water was added and the solution was fortified with addition of $42 \mathrm{mg} \mathrm{NADP} \cdot \mathrm{Na}$ and $20 \mathrm{mg}$ ATP $\cdot 2 \mathrm{Na}$.

Enzyme suspensions (solutions 2 and 3): hexokinase, glucose-6phosphate dehydrogenase and glucose-6-phosphate isomerase enzymes are supplied in the test kit as suspensions in $3.2 \mathrm{~mol} / \mathrm{l} \mathrm{am}-$ monium sulphate solution. Ammonium ion is known to markedly inhibit the mannose-6-phosphate isomerase reaction (15) and in our preliminary experiments we noted that application of these untreated enzyme preparations resulted in a marked slowdown of mannose-6-phosphate isomerase reaction. This inhibition necessitated removal of ammonium sulphate from the enzyme preparations. Solution 2 (containing $285 \mathrm{kU} / 1$ hexokinase and $142 \mathrm{kU} / \mathrm{l}$ glucose-6-phosphate dehydrogenase) and solution 3 (containing $700 \mathrm{kU} / \mathrm{l}$ glucose-6-phosphate isomerase) suspensions were centrifuged in a Coleman Minifuge for eight minutes. The supernatants were removed and the enzyme-rich pellets were resuspended to the original volume with a $1+1$ (by vol) mixture of physiological saline and bovine serum albumin $(10 \mathrm{~g} / \mathrm{l})$.

Mannose-6-phosphate isomerase enzyme suspension (300 kU/l) was used untreated.

Oxidized glutathione (GSSG) was dissolved in distilled water to make $13.5 \mathrm{mmol} / 1$, and glutathione reductase was used as the commercial preparation.

Mannose was stored as a $40 \mathrm{mmol} / \mathrm{l}$ stock solution in water.
Measurement of mannose in serum samples (tab. 1)

Hyperglycaemic samples were diluted with water to a glucose concentration of $5-6 \mathrm{mmol} / \mathrm{l}$. Serum $(200 \mu \mathrm{l})$ or diluted serum (200 $\mu \mathrm{l})$ was mixed with $800 \mu \mathrm{l}$ of solution 1 , followed by $10 \mu \mathrm{l}(2.85 \mathrm{U}$ hexokinase and $1.42 \mathrm{U}$ glucose-6-phosphate dehydrogenase) of solution 2 and $7 \mu \mathrm{l}$ (4.9 $\mathrm{U}$ glucose-6-phosphate isomerase) of solution 3. The mixture was incubated for four minutes at $37^{\circ} \mathrm{C}$ to remove glucose and fructose from the sample. Reduced NADP was then destroyed by adding $0.1 \mathrm{~mol} / 1$ hydrochloric acid $(200 \mu \mathrm{l})$ to the reaction mixture, followed one minute later by addition of $0.1 \mathrm{~mol} / 1$ sodium hydroxide $(120 \mu \mathrm{l})$.

The make-up was then reconstituted by adding $7 \mu 1$ of solution 2 and $5 \mu \mathrm{l}$ of solution 3 , and incubated for four minutes at $37^{\circ} \mathrm{C}$ to eliminate any remaining glucose and fructose. An aliquot $(650 \mu \mathrm{l})$ of the sample was then taken in a separate tube and spiked with $2 \mu 1(0.6 \mathrm{U})$ mannose-6-phosphate isomerase suspension. Ammonium sulphate $(3.2 \mathrm{~mol} / \mathrm{l}, 2 \mu \mathrm{l})$ was added to the remaining aliquot $(650 \mu \mathrm{l})$, and was used as the blank reaction. The $\mathrm{A}_{340}$ difference

Tab. 1 Work-chart of mannose determination.

\begin{tabular}{|c|c|}
\hline Solution 1 (NADP/ATP) & $800 \mu \mathrm{l}$ \\
\hline Sample & $200 \mu \mathrm{l}$ \\
\hline $\begin{array}{l}\text { Solution } 2 \\
\quad \text { (hexokinase/glucose-6-phosphate dehydrogenase) }\end{array}$ & $10 \mu \mathrm{l}$ \\
\hline $\begin{array}{l}\text { Solution } 3 \text { (glucose-6-phosphate isomerase) } \\
\text { Shaking, } 4 \text { min incubation at } 37^{\circ} \mathrm{C}\end{array}$ & $7 \mu \mathrm{l}$ \\
\hline $\begin{array}{l}0.1 \mathrm{~mol} / 1 \mathrm{HCl} \\
\text { Shaking, } 1 \mathrm{~min} \text { incubation }\end{array}$ & $200 \mu \mathrm{l}$ \\
\hline $\begin{array}{l}0.1 \mathrm{~mol} / 1 \mathrm{NaOH} \\
\text { Shaking }\end{array}$ & $120 \mu \mathrm{l}$ \\
\hline $\begin{array}{l}\text { Solution } 2 \\
\quad \text { (hexokinase/glucose-6-phosphate dehydrogenase) }\end{array}$ & $7 \mu l$ \\
\hline $\begin{array}{l}\text { Solution } 3 \text { (glucose-6-phosphate isomerase) } \\
\text { Shaking, } 4 \text { min incubation at } 37^{\circ} \mathrm{C}\end{array}$ & $5 \mu \mathrm{l}$ \\
\hline
\end{tabular}

Shaking, division of the composition in two $650 \mu \mathrm{l}$ portions

Composition

Ammonium sulphate, $3.2 \mathrm{~mol} / 1$

Mannose-6-phosphate isomerase suspension

\begin{tabular}{rr} 
Blank & Sample \\
\hline $\begin{array}{r}650 \mu \mathrm{l} \\
2 \mu \mathrm{l}\end{array}$ & $650 \mu \mathrm{l}$ \\
& $2 \mu \mathrm{l}$
\end{tabular}

Shaking, $10 \mathrm{~min}$ incubation at $37^{\circ} \mathrm{C}$

Shaking, measurement of absorbance at $340 \mathrm{~nm}$

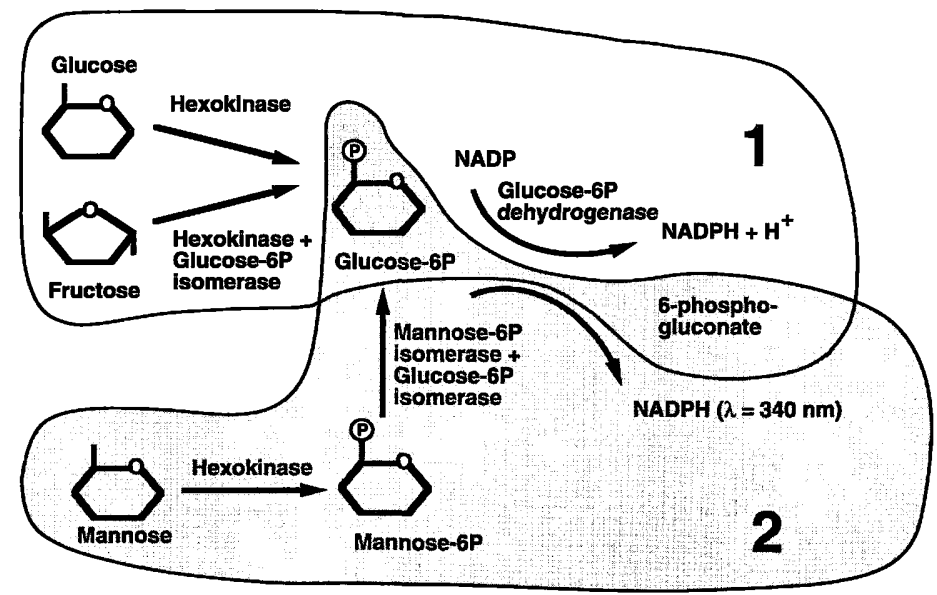

Fig. 1 Enzymatic steps in the removal of glucose and fructose from serum (1) and in the subsequent determination of mannose
(2), NADP $=$ nicotinamide adenine dinucleotide phosphate, $\mathrm{P}=$ phosphate. 
between sample and blank was read after incubation of 10 minutes at $37^{\circ} \mathrm{C}$ in an automatic spectrophotometer (Kone $\mathrm{C}$ clinical analyzer, Kone, Espoo, Finland).

Calculation: The concentration of mannose in serum $(\mu \mathrm{mol} / \mathrm{l}) \mathrm{de}-$ rives from the formula

$$
1100 \times \Delta \mathrm{A}_{340} \text { (sample }- \text { blank) } \times \text { dilution factor. }
$$

\section{Experiments with glutathione reductase}

The experiments were carried out in the reaction mixtures as soon as the absorbance readings for mannose determination were completed. To $650 \mu$ l of reaction mixture, oxidized glutathione (GSSG, $20 \mu \mathrm{l})$ and glutathione reductase $(0.2 \mu \mathrm{l})$ were added, and the change in $\mathrm{A}_{340}$ was recorded for five minutes.

\section{Measurement of mannose-6-phosphate isomerase activity in serum}

To test the presence of mannose-6-phosphate isomerase in samples of serum we removed glucose from samples by allowing $1 \mathrm{ml}$ aliquots of serum to pass through Sephadex G-25 PD-10 columns, equilibrated with $25 \mathrm{mmol} / \mathrm{l}$ triethanolamine buffer, $\mathrm{pH} \mathrm{7.4}$. The column was then rinsed with $1.5 \mathrm{ml}$ buffer solution and the protein fraction collected in $2.7 \mathrm{ml}$ buffer. It was checked that mannose6-phosphate isomerase, added to serum, was recovered in this fraction.

The solutions of the $D$-glucose/ $D$-fructose UV-test kit without modification were used in the measurement of mannose-6-phosphate isomerase activity in the protein fraction.

To solution $1(300 \mu \mathrm{l})$ was added water $(300 \mu \mathrm{l})$, solution 2 (hexokinase/glucose-6-phosphate dehydrogenase, $5 \mu \mathrm{l}$ ), solution 3 (glucose-6-phosphate isomerase, $5 \mu \mathrm{l})$ and mannose $(25 \mu \mathrm{l})$. The mixture was incubated for five minutes at $37^{\circ} \mathrm{C}$ to eliminate glucose, which occurs as a minor impurity in the commercial mannose preparation. Then an aliquot $(500 \mu \mathrm{l})$ of the protein fraction was added and the change in $\mathrm{A}_{340}$ was monitored for 10 minutes. The linear part of the curve was taken to represent mannose-6-phosphate isomerase activity. Another similar reaction mixture omitting the addition of protein fraction served as the blank reaction.

\section{Statistics}

Each single datum of serum mannose concentration represents the average of duplicate samples. The data are presented as mean $\pm \mathrm{SD}, \mathrm{N}=$ number of experiments. The linear correlations were calculated using linear regression analysis. For calculation of the statistical difference Student's unpaired t-test was used and $\mathrm{p}<0.05$ was considered significant.

\section{Results}

Time course of the mannose-6-phosphate isomerase reaction

Addition of mannose-6-phosphate isomerase resulted in a rapid increase in $\mathrm{A}_{340}$ over the first 3 minutes of incubation, followed by a slower increase over the next seven minutes. Beyond the 10 minute time point $\mathrm{A}_{340}$ changed insignificantly (fig. 2). The spectrum characteristics taken at the end of incubation were compatible with the spectrum produced by reduced NADP (fig. 3). An experiment with three further sera produced similar spectrum characteristics and time course profiles.

\section{Experiments with glutathione reductase}

The experiments were conducted to obtain further proof that the increase in $\mathrm{A}_{340}$ that was produced by addition of mannose-6-phosphate isomerase in the reaction mixtures was due to reduction of NADP. The rationale of the test stems from the knowledge that glutathione reductase has the capacity to avidly reduce oxidized glutathione in a reaction that consumes reduced NADP and that the balance strongly favours formation of reduced glutathione (16). We postulated accordingly that any reduced NADP present in our samples should be rapidly oxidized by glutathione reductase in the presence of oxidized glutathione. In these experiments it was noted that addition of oxidized glutathione and glutathione reductase to mannose-6-phosphate isomerase-treated and blank sample reduced $A_{340}$ and that the reaction was rapid (fig. 2). Within two minutes, $A_{340}$ of blank, sample, and sample supplemented with mannose approached each other and no decrease in absorbance was seen in further readings. The glutathione reductase test was carried out in five further samples with similar outcome: $\mathrm{A}_{340}$ declined within two minutes, the absorbances of sample and blank decreased to a similar baseline value and no decline in absorbance was noted in further readings.

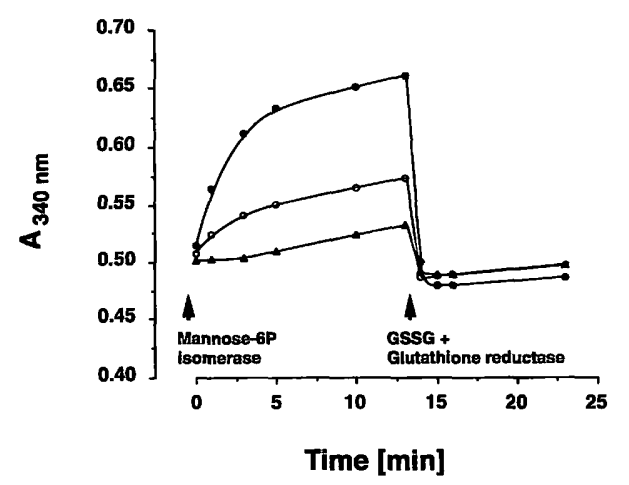

Fig. 2 Time course of absorbance in the determination of mannose in serum (middle curve), serum fortified with $150 \mu \mathrm{mol} / \mathrm{l}$ mannose (upper curve), and blank reaction (addition of mannose6-phosphate isomerase omitted, lower curve). The additions of mannose-6-phosphate isomerase, oxidized glutathione (GSSG), and glutathione reductase are indicated by arrows.

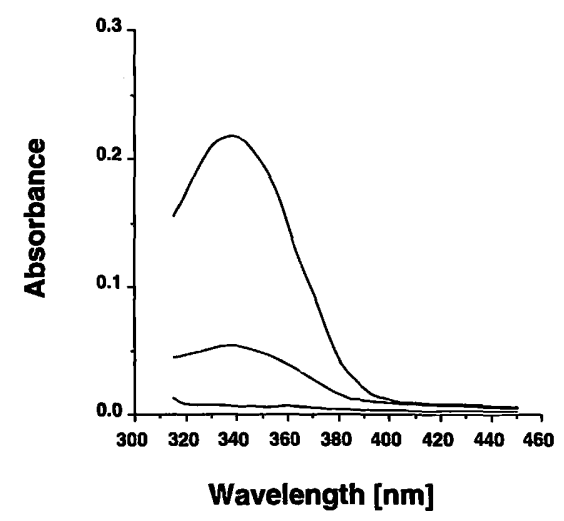

Fig. 3 Spectrum characteristics at the end of incubation of a sample of serum (middle curve), serum fortified with $150 \mu \mathrm{mol} / \mathrm{/} \mathrm{man}$ nose (upper curve), and blank reaction (addition of mannose-6phosphate isomerase omitted, lower curve). 
Method validation

\section{Precision}

The estimation of the between-series variation was obtained from routine unknowns that were measured in duplicate in different runs. The variation coefficient (CV) was $13.5 \%$ (mannose concentration $18.4 \pm 5.5$ $\mu \mathrm{mol} / \mathrm{l}, \mathrm{N}=8$ ) and $10.4 \%$ in samples with a higher mannose concentration $(75.3 \pm 10.3 \mu \mathrm{mol} / \mathrm{l}, \mathrm{N}=12)$. The within-series variation was estimated by running measurements in duplicate. $\mathrm{CV}$ was $6.8 \%$ (mannose concentration $50.7 \pm 43.2 \mu \mathrm{mol} / \mathrm{l}, \mathrm{N}=14)$.

\section{Analytical recovery}

Recovery obtained from samples of serum supplemented with mannose $(200 \mu \mathrm{mol} / \mathrm{l})$ was $90.2 \pm 10.2 \%$ $(\mathrm{N}=28)$.

\section{Linearity}

The linear range was tested by varying the amount of mannose added to a serum sample containing a natural concentration of $25 \mu \mathrm{mol} / 1$ mannose. The recovery showed linearity in the range of $20-220 \mu \mathrm{mol} / 1 \mathrm{man}-$ nose, as depicted in figure 4 . The regression analysis gave $r=0.998$. The regression characteristics for observed/expected were: slope $=0.905$, intercept $=20.7$ $\mu \mathrm{mol} / \mathrm{l}$.

\section{Mannose concentration in serum}

Serum mannose concentration was estimated in blood samples collected during forenoon from healthy female laboratory technicians that had fasted overnight. The concentration was $18.5 \pm 5.5 \mu \mathrm{mol} / 1(\mathrm{~N}=6)$. The blood glucose concentration at the time of collection was 4.4 $\pm 1.0 \mathrm{mmol} / \mathrm{l}$. The mannose concentration was 75.3 $\pm 6.1 \mu \mathrm{mol} / 1(\mathrm{~N}=12)$ in serum of diabetic patients with blood glucose concentration ranging $6.2-16.0 \mathrm{mmol} / \mathrm{l}$. A close positive correlation between serum glucose and mannose concentrations $(\mathrm{r}=0.950)$ was noted (fig. 5).

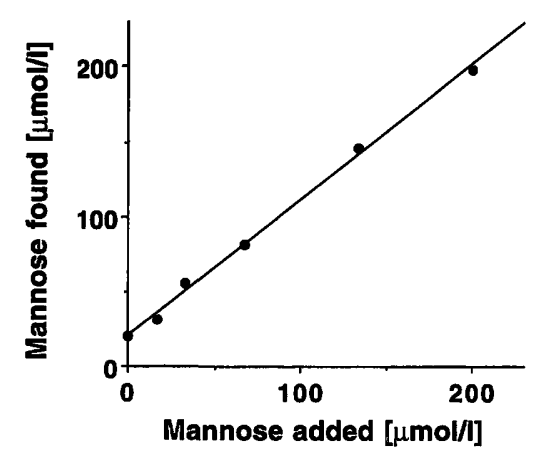

Fig. 4 Linearity of mannose determination in serum, depicted as the relationship between the amount of mannose added (abscissa) and found (ordinate).

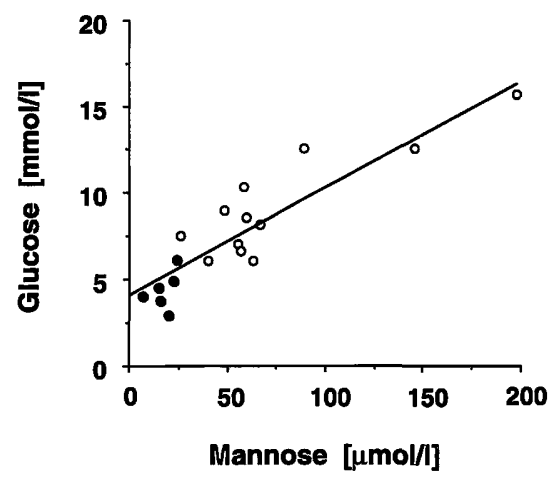

Fig. 5 Correlation between glucose and mannose concentration in serum of non-diabetic subjects (filled circles) and diabetic patients (open circles).

\section{Mannose-6-phosphate isomerase activity in serum}

The measurement of mannose-6-phosphate isomerase activity in serum was deemed necessary since mannose6-phosphate isomerase, if present in serum, may lead to a loss of mannose during the processing of the sample for removal of glucose (tab. 1). Mannose-6-phosphate isomerase activity was measured in 30 samples of serum, including six samples taken from apparently healthy individuals and six patients with diabetes mellitus with blood sugar concentrations $6-12.5 \mathrm{mmol} / \mathrm{l}$. The change in $\mathrm{A}_{340}$ during the photometric measurement was very low, hardly distinguishable from the baseline level. The highest activity encountered was $3 \mathrm{U} / \mathrm{l}$. The experiments indicated that the mannose-6-phosphate isomerase activity in the samples of serum, if any, was too low for its accurate measurement.

Rationale of another set of experiments was the hypothesis of encountering a sample of serum with considerable mannose-6-phosphate isomerase activity. In these experiments we determined the concentration of mannose in samples supplemented with mannose-6-phosphate isomerase (100 and $200 \mathrm{U} / 1)$ and mannose (200 $\mu \mathrm{mol} / \mathrm{l})$. The presence of $100 \mathrm{U} / 1$ mannose-6-phosphate isomerase in the sample led to a loss of $10 \mu \mathrm{mol} / 1 \mathrm{man}$ nose ( $4.0 \%$ of the amount of mannose in the sample). Presence of $200 \mathrm{U} / 1$ mannose-6-phosphate isomerase led to a loss of $17.8 \mu \mathrm{mol} / 1$ mannose $(7.1 \%$ of the amount of mannose in the sample). It was inferred that the loss of mannose in samples with mannose-6-phosphate isomerase activity up to $200 \mathrm{U} / 1$ in serum would be gradeable but remain moderate.

\section{Discussion}

Removal of glucose using hexokinase and glucose-6phosphate dehydrogenase and disintegration by acidification of NADPH produced, emerged as a functionable and efficient procedure in the preparation of samples for the determination of mannose. The experience that 
glucose-6-phosphate dehydrogenase, while highly active with glucose-6-phosphate, is inactive with mannose-6phosphate (17) makes it likely that no loss of mannose was taking place during the procedure. In this rating the present procedure may be superior to earlier procedures relying on glucose oxidase, an enzyme with broader substrate specificity. The power of hexokinase to phosphorylate both anomeric forms of mannose (18) is an advantage as it ensures that the phosphorylation of mannose quickly runs to completion. The strict substrate specificity of mannose-6-phosphate isomerase to convert mannose-6-phosphate to fructose-6-phosphate (14) imparts high specificity to the determination of mannose.

Addition of mannose-6-phosphate isomerase, initiating the final step in the procedure, produced an increase in $\mathrm{A}_{340}$ that appeared to follow first order kinetics. The time course was similar in natural samples and in samples supplemented with mannose. The spectrum data and the outcome of the glutathione/glutathione reductase test provided unequivocal evidence that the increase in absorbance was due to accumulation of reduced NADP. A gradual, albeit moderate, increase in $\mathrm{A}_{\mathbf{3 4 0}}$ was also noted in the blank reaction (mannose-6-phosphate isomerase omitted). The cause of the increase in the blank reaction remained unknown, but we found that leftover glucose and fructose stemming from an incomplete glucose removal step may occasionally form a source for the elevation.

The perspective of confronting samples with high mannose-6-phosphate isomerase activity is a crucial issue, facing enzymatic methods of mannose determination of the present category. It was reassuring to note that our study with 30 test sera produced no evidence for the presence of mannose-6-phosphate isomerase in serum. Furthermore, our search in the Medline library did not track down any report on occurrence of mannose-6phosphate isomerase in serum. The data obtained seem to imply that occurrence in serum of the enzyme may remain a hypothetical consideration. Brain, muscle, kidney, liver and erythrocytes are tissues rich in mannose6-phosphate isomerase (19) and our study did not incor-

\section{References}

1. Heiskell CL, Carpenter CM, Weimer HE, Nakagawa S. Serum glycoproteins in infectious and inflammatory diseases. Ann NY Acad Sci 1961; 94:183-209.

2. McMillan DE. Changes in serum proteins and protein-bound carbohydrates in diabetes mellitus. Diabetologia 1970; 6:597-604.

3. Radhakrishnamurthy B, Berenson GS, Pargaonkar PS, Voors AW, Srinivasan SR, Plavidal F, et al. Serum-free and proteinbound sugars and cardiovascular complications in diabetes mellitus. Lab Invest 1976; 34:159-65.

4. Ashwell G, Steer CJ. Hepatic recognition and catabolism of serum glycoproteins. J Am Med Assoc 1981; 246:2358-64.

5. Akazawa S, Metzger BE, Freinkel N. Relationships between glucose and mannose during late gestation in normal preg- porate samples collected under acute conditions of these tissues.

The mannose concentrations found in normal individuals are not unlike the values found in an earlier study using an enzymatic method (6), but somewhat lower than the concentrations found with mass spectrometry $(11,20,21)$. The test subjects singled out for the present study were lean fasting females under 45 years of age and it is possible that disparities in the test subject selection and sample collection may account for at least a part of the departure. High mannose concentrations found in hyperglycaemic patients tally with earlier data from several laboratories dealing with the concentration of mannose in diabetes mellitus $(3,5,7,8,20)$. The correlation found between mannose and glucose is in compliance with earlier reports of a positive relationship between the concentrations of mannose and glucose in serum $(5,20)$.

An enzymatic assay of $D$-mannose in serum using glucose-6-phosphate dehydrogenase, glucose-6-phosphate isomerase and mannose-6-phosphate isomerase was issued quite recently (22). In the assay, the content of glucose was minimized by using glucose-specific glucokinase and glucose-6-phosphate dehydrogenase. Treatment with weak ion exhanger depleted the samples from anionic reaction products, including reduced NADP. In keeping with the report, our study supports the view that the use of glucose-6-phosphate dehydrogenase and mannose-6-phosphate isomerase provides a sound footing for a specific and high sample throughput measurement of mannose.

Our knowledge of mannose metabolism in human disease is limited. However, the few studies so far conducted have produced intriguing observations on serum mannose concentrations in diabetes mellitus, Candida infection, renal disease, and hyperlipaemia associated with chronic nephritis $(3,5,8,20,21)$. Development of simple enzymatic tests may promote investigation of mannose and other members of the interesting family of non-glucose polyols (monosaccharides) that circulate in serum and body fluids. nancy and pregnancy complicated by diabetes mellitus: concurrent concentrations in maternal plasma and amniotic fluid. J Clin Endocrinol Metab 1986; 62:984-9.

6. Soyama K. Enzymatic determination of D-mannose in serum. Clin Chem 1984; 30:293-4.

7. Aloia JF. Monosaccharides and polyols in diabetes mellitus and uremia. J Lab Clin Med 1973; 82:809-17.

8. Monson TP, Wilkinson KP. Mannose in body fluids as an indicator of invasive candidiasis. J Clin Microbiol 1981; 14:557-62.

9. Yoshioka S, Saitoh S, Seki S, Seki K. Concentrations of nonglucose polyols in serum and cerebrospinal fluid from apparently healthy adults and children. Clin Chem 1984; 30:18891. 
10. Kusmierz J, DeGeorge JJ, Sweeney D, May C, Rapoport SI. Quantitative analysis of polyols in human plasma and cerebrospinal fluid. J Chromatogr 1989; 497:39-48.

11. Pitkänen E, Kanninen T. Determination of mannose and fructose in human plasma using deuterium labelling and gas chromatography/mass spectrometry. Biol Mass Spectrom 1994; 23:590-5.

12. Keilin D, Hartree EF. Specificity of glucose oxidase (notatin). Biochem J 1952; 50:331-41.

13. Lowry OH, Passonneau JV. A flexible system of enzymatic analysis. New York and London: Academic Press, 1972:1112.

14. Gawehn K. D-Mannose and D-mannose-6-phosphate. In: Bergmeyer HU, editor. Methods of enzymatic analysis. Weinheim: Verlag Chemie GmbH, 1984; 6:262-7.

15. Slein MW. Phosphohexoisomerases from muscle. In: Colowick SP, Kaplan NO, editors. Methods in enzymology. New York: Academic Press, 1955; 1:299-304.

16. Schirmer RH, Krauth-Siegel RL, Schulz GE. Glutathione reductase. In: Dolphin D, Avramovic O, Poulson R, editors. Glutathione. Chemical, biochemical, and medical aspects. New York: John Wiley \& Sons, 1989: 553-96.

17. Greiling H, Kisters R. Untersuchungen über die Substratspezifität der Glucose-6-phosphat-dehydrogenase. Hoppe-Seylers $Z$ Physiol Chem 1965; 341:172-84.
18. Giroix M-H, Sener A, Malaisse WJ. Anomeric specificity of mannose phosphorylation by hexokinase. Biochim Biophys Acta $1985 ; 829: 354-7$

19. Bruns FH, Noltmann E, Willemsen A. Phosphomannose-isomerase 1. Über die Aktivitätsmessung und die Sulfhydrylsowie die Metallabhängigkeit der Enzymwirkung in einigen tierischen Geweben. Biochem Z 1958; 330:411-20.

20. Pitkänen E. Mannose, mannitol, fructose and 1,5-anhydroglucitol concentrations measured by gas liquid chromatography/ mass spectrometry in blood plasma of diabetic patients. Clin Chim Acta 1996; 251:91-103.

21. Pitkänen E. Proteinuria and plasma hexosugars in early-stage glomerulonephritis. Clin Nephrol 1996; 45:226-9.

22. Etchison JR, Hudson HF. Enzymatic assay of D-mannose in serum. Clin Chem 1997; 43:533-8.

Received April 28/July 18, 1997

Corresponding author: Dr. E. Pitkänen, Department of Clinical Chemistry, Helsinki University Hospital, Haartmaninkatu 4, FIN-00290, Helsinki, Finland 